\title{
THE EFFECT OF PARMANIL ON CEREBRAL CIRCULATION
}

\author{
TOYOZO AIZAWA*, Y. GOTO, Y. TAZAKI, H. MAKINO, H. NAKAZATO, \\ T. AOKI, H. OHBAYASHI, M. UMEHARA, S. HAMAYA, \\ M. SAKURAI, K. MURAKAMI, S. EBIHARA, M. \\ KAWAMURA, T. OKADA, S. KITAMURA, \\ and $Y$. TSUKABE \\ Department of Internal Medicine, School of Medicine \\ Keio University
}

(Received on April 16, 1959)

\section{INTRODUCTION}

Parmanil consists of oxyethyl-theophylline and nucleoside containing adenosine and it is well known that the preparation is effective in the treatment of various heart disease and coronary artery diseases as well as cerebral vascular diseases. Oxyethyl-theophylline has a strong action in dilating blood vessels and diuresis. It dilates or moderates peripheral blood vessels and thus it is considered to be effective in the treatment of hypertension, arteriosclerosis, embolism and infarction etc. The nucleoside is an extract of the skeletal muscles and organs of mammal and it corresponds to $4 \mathrm{mg}$ of adenosine for each tablet. It is considered that the nucleoside has a strong effect in dilating central vessels and increases cerebral blood flow and moreover it also moderates arteriolospasm. The effects of each component of Parmanil strengthen each other, thus, it can be considered that the administration of this preparation may be more effective than that of a theophylline derivative alone.

\section{CASE REPORT}

The authors observed the clinical effect of Parmanil in 5 cases of disturbance of cerebral blood vessel, after an apoplectic attack. Parmanil was administered in the dose of 3 tablets daily by mouth ( 1 tablet contains $220 \mathrm{mg}$ oxyethyl-theophylline and nucleoside, corresponding to $4 \mathrm{mg}$ adenosine).

(Case 1) 68-years-old Cerebral infarction

The patient had had the left hemiplegia for the past two years and had the

* Professor of Internal Medicine. 
right hemiplegia since last year. The movement of the right arm and leg was almost impossible but he was able to raise or bend the left arm in the medium rate. The grasping power was markedly decreased and a disturbance was observed in the small movement of fingers. Furthermore, the patient had dysarthria and an incontinence of emotion. The patient was in the depressive state. Parmanil was administered for 5 days then the words became audible from the second day and the patient mentioned that the feeling also became more fresh. Although the patient wanted to continue the therapy, the administration had to be discontinued as the blood pressure raised from $126 / 56 \mathrm{mmHg}$ to $190 / 80 \mathrm{mmHg}$ during therapy. The blood pressure returned to the former value afterwards.

\section{(Case 2) 61-years-old Cerebral infarction}

The patient was affected with an attack of cerebral apoplexy one month ago and had a disturbance of consciousness. At that time the blood pressure was $130 / 100 \mathrm{mmHg}$. Thenceforth the patient had the left hemiplegia and he could not move the upper arm. The leg could be bent slightly only at the knee and a moderate disturbance of speech was observed. The patient also had mental disturbances, that was, sleeplessness, excitement, disturbance of orientation hallucination, and illusion were observed. After 4 days of administration of Parmanil an improvement was seen in the sleeplessness and the pain of the left leg caused by the passive extention and contraction. Moreover, the disturbance of orientation and illusion were also relieved. In the dysarthria an improvement was observed to a certain extent.

\section{(Case 3) 47-years-old Cerebral infarction}

The patient had the right hemiplegia ten years ago but it markedly recovered to such extent that he could walk with slight claudication and the patient had been working up to recent time. Two months ago the patient was affected with an attack of cerebral apoplexy on the street and he had intensive disturbance of speech and marked hemiplegia in the right side ever since. The patient was able to get up but he could not walk at all. After one week of Parmanil therapy, the patient became able to walk and the disturbance of movement of the right arm was gradually improved while the treatment was made for 2 months, that was, writing letters and arm raising (to the medium extent) became possible. The blood pressure was around $110 / 80 \mathrm{mmHg}$ and it did not change markedly during administration. 
(Gase 4)

56-years-old

Cerebral infaretion

The patient had had hypertension for the past several years (at the highest $240 / 130 \mathrm{mmHg}$ ). Two months ago the patient was suddenly affected with an incomplete paralysis in the right side and disturbance of speech was seen. $\mathrm{He}$ complained about headache and dizziness. Although the walk had been disturbed, the movement was comparatively smooth and the speech, though not clear, was about understandable. Parmanil was administered for fourty days but no marked change was observed except a slight improvement of walking.

(Case 5)

58-years-old Cerebral infarction

For the past 3 month the patient had had gradual progress of the disturbance of speech and movement in the right arm and leg. He often had clouding of consciousness at that time and the right hemiplegia was observed in medium rate.

Table 1

Effect of Parmanil on Disturbance of Cerebral Circulation

\begin{tabular}{|c|c|c|c|c|c|c|}
\hline \multicolumn{2}{|c|}{ Case No. } & 1 & 2 & 3 & 4 & 5 \\
\hline \multicolumn{7}{|l|}{ Name } \\
\hline \multicolumn{2}{|l|}{ Sex } & 今 & 昘 & 今 & 占 & 古 \\
\hline \multicolumn{2}{|l|}{ Age } & 68 & 61 & 47 & 56 & 58 \\
\hline \multicolumn{2}{|c|}{ Illness } & $\begin{array}{l}\text { Cerebral } \\
\text { infarction }\end{array}$ & $\begin{array}{l}\text { Cerebral } \\
\text { infarction }\end{array}$ & $\begin{array}{l}\text { Cerebral } \\
\text { infarction }\end{array}$ & $\begin{array}{l}\text { Cerebral } \\
\text { infarction }\end{array}$ & $\begin{array}{l}\text { Cerrebral } \\
\text { infarction }\end{array}$ \\
\hline \multicolumn{2}{|c|}{ Administration } & before after & before after & before after & before after & before ofter \\
\hline \multirow{6}{*}{$\begin{array}{l}\text { Main } \\
\text { symptoms }\end{array}$} & Complaint & $+\quad+$ & $+\quad-$ & $-\quad-$ & $+\quad+$ & + \\
\hline & Mental & $H+$ & $+\quad \pm$ & $-\quad-$ & $-\quad-$ & $H \quad H$ \\
\hline & Movement & \# H & \# $\quad$ H & H & + & $H$ \\
\hline & Sensation & $+\quad+$ & $+\quad+$ & - & - & + \\
\hline & Speech & + & + & $H$ & $+\quad+$ & $H$ \\
\hline & $\begin{array}{l}\text { Blood } \\
\text { pressure }\end{array}$ & $126 / 56 \quad 196 / 80$ & $110 / / 60 / 710 / / 70$ & $110 / 80 / 80$ & $136 / 180 / / 110$ & $144 / 84 \quad 188 / 64$ \\
\hline \multicolumn{2}{|c|}{ Side-effect } & $(-)$ & $(-)$ & $(-)$ & $(-)$ & $(-)$ \\
\hline \multicolumn{2}{|c|}{ Duration of therapy } & $\begin{array}{l}3 \text { tabs. } \\
5 \text { days }\end{array}$ & $\begin{array}{l}3 \text { tabs. } \\
4 \text { days }\end{array}$ & $\begin{array}{l}3 \text { tabs. } \\
70 \text { days }\end{array}$ & $\begin{array}{l}3 \text { tabs. } \\
40 \text { days }\end{array}$ & $\begin{array}{l}3 \text { tabs. } \\
14 \text { days }\end{array}$ \\
\hline \multirow{3}{*}{ Effect } & Subjective & + & - & - & - & - \\
\hline & Objective & + & \pm & $?$ & - & - \\
\hline & Collective & + & \pm & $?$ & - & - \\
\hline
\end{tabular}


Pathological reflexes and disturbance of speech were also seen. The blood pressure was $144 / 84 \mathrm{mmHg}$. Subsequently the clouding of consciousness increased gradually and sometimes the patient fell into a coma. Parmanil was administered continuousiy for 2 weeks though no improvement was observed and the patient died after one month.

\section{Clinical Summary: (Table 1)}

(1) During Parmanil administration the ability of movement and walk was improved in 2 cases. However, these improvements were obtained after prolonged administration extending over 40 or 70 days so that it can not be concluded that the improvement was particularly due to Parmanil because the treatment was made at the same time with other medications and spontaneous recovery also must be considered.

(2) No effect was observed by Parmanil in cases of comatose or of clear consciousness, however, Parmanil was effective in 2 cases of which had a slight mental disturbance in activation of psychomotor and moderation of mental condition with short termed administration.

(3) In one case the disturbance of speech was improved clearly after Parmanil, but in the other cases the effect could not be seen or was obscure.

(4) The direct effect of Parmanil on the subjective symptoms such as headache and others was not obvious.

(5) An increase of blood pressure was observed in 4 cases however, no other side-effect was seen.

\section{EFFECT OF PARMANIL OF THE CEREBRAL CIRCULATION AND METABOLISM}

(1) Fifteen subjects or $32 \sim 71$ years old were studied (average 52 years old). The subjects had been found to have various diseases, the main symptom was hypertension. Investigation was made on the cerebral circulation and metabolism before and after Parmanil administration. Determination was done on the basis of $\mathrm{NO}_{2}$-method by Kety and Schmidt ${ }^{1}$. Collecting samples and calculation were made according to the authors modified 2 . The patients were laid down quietly in the fasting time and the blank value (control) was initially determined. Then 12 ampules of Parmanil dissolved in $20 \mathrm{cc}$ of physiological saline were slowly injected intravenously and the cerebral circulation was determined from 3-5 minutes after injection by observing the process of $\mathrm{NO}_{2}$-desaturation (Clerke) ${ }^{3)}$.

The blood gas was analyzed by Van Slyke-Neil's method. The $\mathrm{pH}$ was determined by glass-electrode method and the temperature was corrected by Rosenthal's 
method. The $\mathrm{CO}_{2}$-tension in arterial blood was calculated by the use of Singer's Nomogram. Glucose in the blood by Somogyi's method, lactic acid by MendelGoldscheider method and pyruvic acid by Yoshikawa-Shimiza's method were re= spectively determined.

Terms and units of the determination in the cerebral circulation and metabolism are as follows:

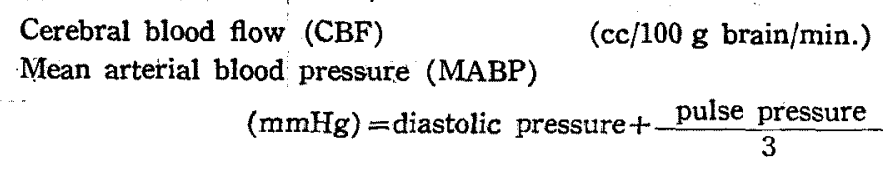

Cerebral vascular resistance (CVR)

$$
(\mathrm{mmHg} / \mathrm{cc} / 100 \mathrm{~g} \text { brain } / \mathrm{min} .)=\frac{\mathrm{MABP}}{\mathrm{CBF}}
$$

Artery-vein difference of oxygen in the brain $\left(\mathrm{A}-\mathrm{VO}_{2}\right)$ (vol. \%)

Oxygen supply in the brain $\left(\mathrm{CDO}_{2}\right)$

$$
(\mathrm{cc} / 100 \mathrm{~g} \text { brain } / \mathrm{min} .)=\mathrm{CBF} \times \frac{\mathrm{AO}_{2}}{100}
$$

Oxygen consumption in the brain $\left(\mathrm{CMRO}_{2}\right)$

$$
(\mathrm{cc} / 100 \mathrm{~g} \text { brain } / \mathrm{min} .)=\mathrm{CBF} \times \frac{\mathrm{A}-\mathrm{VO}_{2}}{100}
$$

Oxygen up-take in the brain $\left(\mathrm{ERO}_{2}\right)(\%)$

$$
\frac{\mathrm{CMRO}_{2}}{\mathrm{CDO}_{2}} \times 100
$$

Cerebral respiratory quotient (CRQ)

$\frac{\mathrm{V}-\mathrm{ACO}_{2}}{\mathrm{~A}-\mathrm{VO}_{2}}$

Glucose concentration in the blood (gl)

$(\mathrm{mg} / \mathrm{dl})$

Glucose consumption in the brain (CMRgl)

$$
(\mathrm{mg} / 100 \mathrm{~g} \text { brain } / \mathrm{min} .)=\mathrm{CBF} \times \frac{\mathrm{A}-\mathrm{Vgl}}{100}
$$

( $A$ and $\mathrm{V}$ indicate the contents of each substance in the femoral artery and internal jugular vein)

(2) Result: The change of cerebral circulation before and after Parmanil are shown in Table 2. No marked change was observed in the cerebral blood flow (47.5 to 46.5 ), mean arterial blood pressure (117 to 118 ) and cerebral vascular resistsnce (2.61 to 2.63$)$. ( $\mathrm{P}>0.2)$

Table 3 shows the quantities of the gases in the arterial blood. Although oxygen content in the arterial blood showed a significant decrease (16.48 to 15.64) $(0.05>\mathrm{P}>0.01)$, no particular change was observed in the $\mathrm{CO}_{2}$ content $(47.52$ to $47.95), \mathrm{pH}$ (7.43 to 7.43) and the partial pressure of $\mathrm{CO}_{2}(34.2$ to 33.5). ( $\mathrm{P}>0.2)$

Table 4 shows the metabolic condition of oxygen gas in the brain. There some-decrease was observed in the A-V difference of oxygen (6.71 to 6.54), cerebral oxygen consumption (3.20 to 2.92 ) and oxygen supply (7.86 to 7.06 ), though, these 
Table 2

Effect of Parmanil on Cerebral Circulation

\begin{tabular}{l|c|c|c|c}
\hline & C B F & MABP & C V R \\
\hline Number of case 15 & $\begin{array}{l}\text { Mean value } \\
\text { before administration }\end{array}$ & 47.5 & 117 & 2.61 \\
\hline Average age 52 years & $\begin{array}{l}\text { Mean value } \\
\text { after administration }\end{array}$ & 46.5 & 118 & 2.63 \\
\hline & P $>0.2$ & P>0.2 & P >0.2 \\
\hline
\end{tabular}

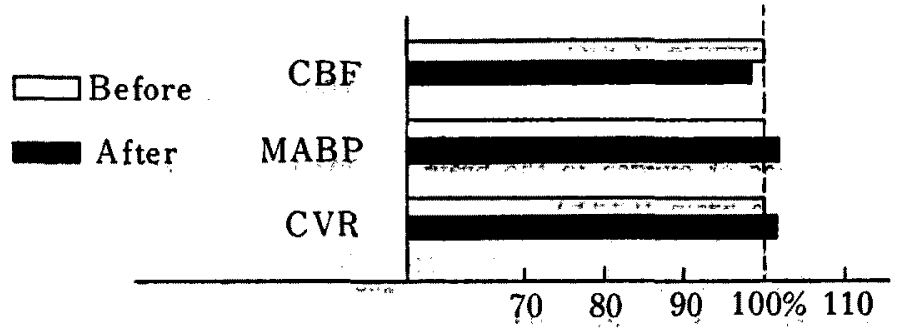

Table 3

Effect of Paxmanil on Gases in the Arterial Blood

\begin{tabular}{l|c|c|c|c}
\hline \hline & $\mathrm{AO}_{2}$ & $\mathrm{ACO}_{2}$ & $\mathrm{pH}$ & $\mathrm{PaCO}_{2}$ \\
\hline $\begin{array}{l}\text { Main value } \\
\text { before administration }\end{array}$ & 16.48 & 47.52 & 7.43 & 34.2 \\
\hline $\begin{array}{l}\text { Mean value } \\
\text { after administration }\end{array}$ & 15.64 & 47.95 & 7.43 & 33.5 \\
\hline & $0.05>\mathrm{P}>0.01$ & $\mathrm{P}>0.2$ & $\mathrm{P}>0.2$ & $\mathrm{P}>0.2$ \\
\hline
\end{tabular}

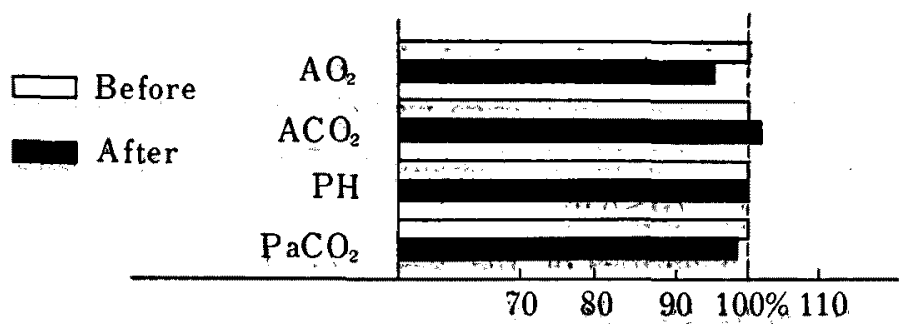

differences were not significant. $(P>0.2)$

Table 5 shows the cerebral carbohydrate metabolism. There a slight increase was seen only in the glucose consumption and no certain change could bo abserved in the lactic acid and pyruvic acid. 
Table 4

Effect of Parmanil on Cerebral Gas Metabolism

\begin{tabular}{l|c|c|c|c|c}
\hline & $\mathrm{A}-\mathrm{VO}_{2}$ & $\mathrm{CMRO}_{2}$ & $\mathrm{CDO}_{2}$ & $\mathrm{ERO}_{2}$ & $\mathrm{CRQ}$ \\
\hline $\begin{array}{l}\text { Mean value } \\
\text { before administration }\end{array}$ & 6.71 & 3.20 & 7.86 & 40.6 & 1.02 \\
\hline $\begin{array}{l}\text { Mean value } \\
\text { after administration }\end{array}$ & 6.54 & 2.92 & 7.06 & 41.6 & 0.99 \\
\hline & $\mathrm{P}>0.2$ & $\mathrm{P}>0.2$ & $0.1>\mathrm{P}>0.05$ & $\mathrm{P}>0.2$ & $\mathrm{P}>0.2$ \\
\hline
\end{tabular}

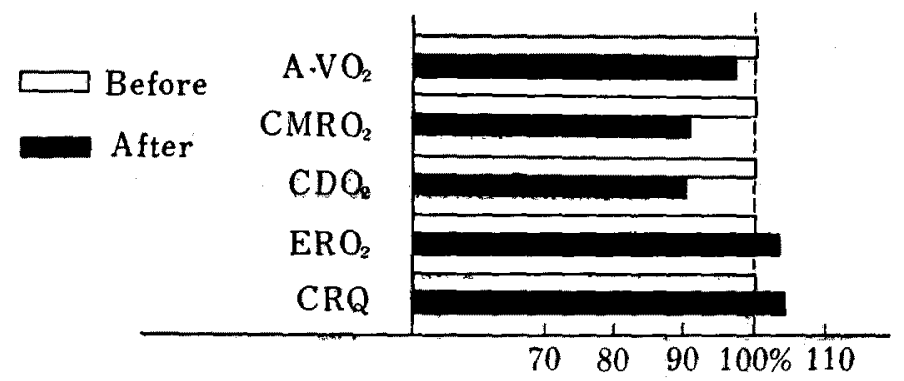

Table 5

Effect of Parmanil on Carbohydrate Metabolism in the Brain

\begin{tabular}{l|c|c|c}
\hline & $\mathrm{Agl}$ & $\mathrm{A}-\mathrm{Vgl}$ & $\mathrm{CMRgl}$ \\
\hline $\begin{array}{l}\text { Mean value } \\
\text { before administration }\end{array}$ & 110 & 9 & 4.28 \\
\hline $\begin{array}{l}\text { Mean value } \\
\text { after administration }\end{array}$ & 112 & 10 & 4.67 \\
\hline
\end{tabular}

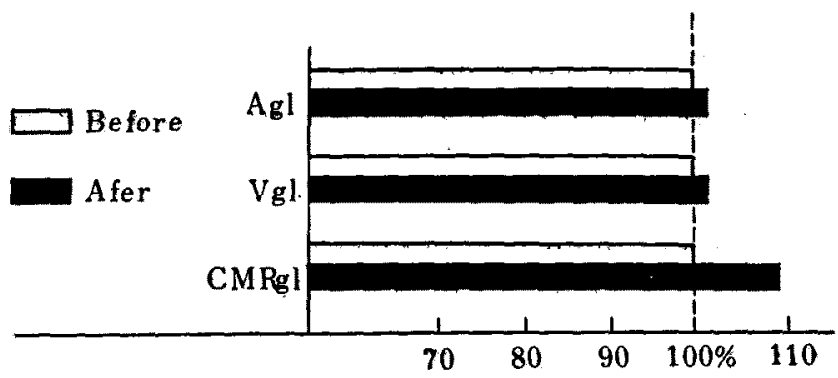

Investigation was made individually on the change of the cerebral circulation (Table 6). In the group receiving one ampule of Parmanil (indicated with dotted line) the cerebral blood flow decreased in all cases and the cerebral vascular resistance increased in most cases. The oxygen consumption in the brain did not 
change or showed only a slight decrease. On the other hand the group treated with two ampules of Parmanil did not show a certain change in the cerebral blood flow, that was, some showed an increase and the other showed a decrease. However, in four 'cases which showed a decrease of the cerebral blood flow before administration the blood flow increased apparently after Parmanil. In the four cases which showed a marked increase in the cerebral blood flow after adminis. tration of Parmanil, two of them had been found to have cerebrel embolism and the other two had had hypertension associated with arteriosclerosis. Thus, it can be deducted that Parmanil may improve the cerebral blood flow in these cases. However, no difference was observed in the cerebral vascular resistance and oxygen consumption in the brain with the dosages and cases.

Table 6

Cerebral Circulation Before and After Parmanil

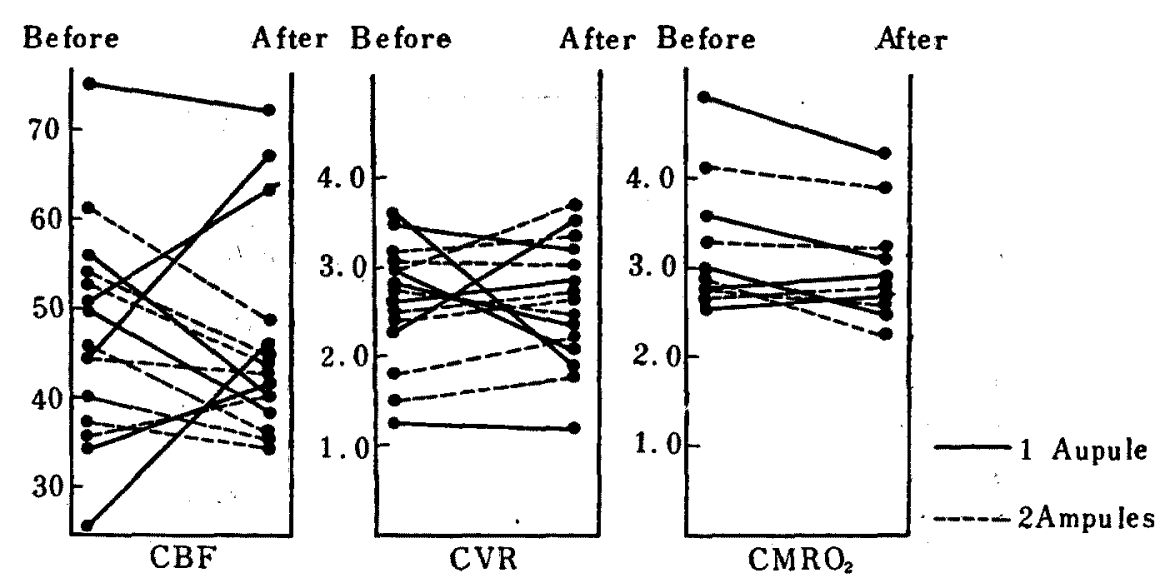

To analyze the effect of Parmanil, components, oxyethyl-theophylline and nucleoside containing adenosine on the cerebral circulation and metabolism were investigated respectively.

\section{EFFECT OF OXYETHYL-THEOPHYLLINE ON THE CEREBRAL CIRCULATION AND METABOLISM}

In this study oxyphylline (Sankyo) was used for oxyethyl-theophylline. Two hundred and twenty milligrams of oxyphylline dissolved into $20 \mathrm{cc}$ physiological saline was slowly injected intravenously and the cerebral circulation and metabolism were investigated before and after injection. The study was made of 5 patients who were average 53 years old and had been found to have mainly hypertension. As shown in Table 7, the cerebrel blood flow showed a meaningful decrease after 
injection (55.6 to 46.9$)(0.05>P>0.01)$, and this effect seems to have the same tendency as that of theophylline-ethylendiamine. Although the mean arterial blood pressure (116 to 113 ) and cerebral vascular resistance (2.14 to 2.44 ) showed some change at the same time, those differences were not significant. $(P>0.05)$

In the investigation of gases in the arterial blood an increase of oxygen content, a depression of $\mathrm{CO}_{2}$ content and a decrease of the $\mathrm{CO}_{2}$ tension were observed. Those changes proved that there a tendency of hyperventilation occured but no

Table 7

Effect of Oxyphylline on Cerebral Circulation and Gases in the Arterial Blood

\begin{tabular}{c|c|c|c|c}
\hline \hline $\begin{array}{c}\text { Number of case } \\
15\end{array}$ & $\begin{array}{l}\text { Mean value } \\
\text { before administration }\end{array}$ & 55.6 & 116 & $\mathrm{CBF}$ \\
\hline \begin{tabular}{c|c|c|c} 
Average age \\
53 years
\end{tabular} & $\begin{array}{l}\text { Mean value } \\
\text { after administration }\end{array}$ & 46.9 & 113 & 2.24 \\
\hline & $\mathrm{AO}_{2}$ & $\mathrm{ACO}_{2}$ & $\mathrm{pH}$ & $\mathrm{PaCO}_{2}$ \\
\hline \hline & 16.94 & 47.01 & 7.43 & 35.3 \\
\hline $\begin{array}{c}\text { Mean value } \\
\text { before administration }\end{array}$ & 17.01 & 45.73 & 7.44 & 33.3 \\
\hline $\begin{array}{c}\text { Mean value } \\
\text { after administration }\end{array}$ & $\mathrm{P}>0.2$ & $\mathrm{P}>0.2$ & $\mathrm{P}>0.2$ & $0.2>\mathrm{P}>0.1$ \\
\hline
\end{tabular}

Table 8

Effect of Oxyphylline on Cerebral Metabolism

\begin{tabular}{l|c|c|c}
\hline & $\mathrm{Agl}$ & $\mathrm{A}-\mathrm{Vgl}$ & $\mathrm{CMRgl}$ \\
\hline $\begin{array}{l}\text { Mean value } \\
\text { before administration }\end{array}$ & 84 & 7 & 3.89 \\
\hline $\begin{array}{l}\text { Mean value } \\
\text { after administration }\end{array}$ & 73 & 4 & 1.88 \\
\hline
\end{tabular}

\begin{tabular}{l|c|c|c|c|c}
\hline & $\mathrm{A}^{-\mathrm{VO}_{2}}$ & $\mathrm{CMRO}_{2}$ & $\mathrm{CDO}_{2}$ & $\mathrm{ERO}_{2}$ & $\mathrm{CRQ}$ \\
\hline $\begin{array}{c}\text { Mean value } \\
\text { before administration }\end{array}$ & 6.52 & 3.60 & 9.41 & 38.8 & 1.00 \\
\hline $\begin{array}{l}\text { Mean value } \\
\text { after administration }\end{array}$ & 6.86 & 3.21 & 8.01 & 40.5 & 1.01 \\
\hline & $\mathrm{P}>0.2$ & $\mathrm{P}>0.2$ & $0.1>\mathrm{P}>0.05$ & $\mathrm{P}>0.2$ & $\mathrm{P}>0.2$ \\
\hline
\end{tabular}


significance could be observed in each ehange, thus, it is impossible to explain the change of cerebral eirculation with this result. Therefore, it can be considered that the change may be, like a change occurs after administration of theophyllineethylendiamine, due to the decrease of the cerebral blood flow caused by a certain mechanism.

The effect of exyethyl-theophylline on cerebral metabolism is shown in Table 8. A-V difference of glucose (average 7 to 4 ) and cerebral glucose consumption (3.89 to 1.88) decreased after injection, though, these were not meaningful change. No particular change was observed in the A-V difference of oxygen, oxygen consumption, oxygen supply, oxygen up-take in the brain and the cerebral respiratory quotient. $\quad(\mathrm{P}>0.2)$

\section{EFFECT OF LACARNOL ON CEREBRAL CIRCULATION AND METABOLISM}

Five subjects of average 39 years ald received $10 \mathrm{cc}$ of Lacarnol-Forte intravenously. Then the cerebral blood flow showed a decrease from avererage 54.8 to 45.3, however, the change was not significant statistically $(0.1>\mathrm{P}>0.05)$. The mean arterial blood pressure did not show any particular change (128 to 129). The cerebral vascular resistance increased from 2.45 to 2.95 though it was neither meaningful change. As shown in Table 9, no marked change was observed in the oxygen content in the arterial blood, $\mathrm{CO}_{2}$ content, $\mathrm{pH}$ and the partial pressure of $\mathrm{CO}_{2}$. $\quad(\mathrm{P}>0.2)$

Table 9

Effect of Lacarnol on Cerebral Circulation and Gases in the Arterial Blood

\begin{tabular}{c|l|c|c|c}
\hline \hline \multirow{2}{*}{$\begin{array}{c}\text { Number of case } \\
15\end{array}$} & $\begin{array}{l}\text { CBF } \\
\text { Mefore value } \\
\text { before admistration }\end{array}$ & 54.8 & MABP & CVR \\
\hline $\begin{array}{c}\text { Average age } \\
39\end{array}$ years & $\begin{array}{l}\text { Mean value } \\
\text { after administration }\end{array}$ & 45.3 & 128 & 2.45 \\
\hline & $0.1>\mathrm{P}>0.05$ & $\mathrm{P}>0.2$ & $0.1>\mathrm{P}>0.05$ \\
\hline
\end{tabular}

\begin{tabular}{l|c|c|c|c}
\hline \hline & $\mathrm{AO}_{2}$ & $\mathrm{ACO}_{2}$ & $\mathrm{pH}$ & $\mathrm{PaCO}_{2}$ \\
\hline $\begin{array}{l}\text { Mean value } \\
\text { before administration }\end{array}$ & 17.65 & 49.58 & 7.39 & 39.9 \\
\hline $\begin{array}{l}\text { Mean value } \\
\text { after administration }\end{array}$ & 17.47 & 50.04 & 7.39 & 40.8 \\
\hline & $\mathrm{P}>0.2$ & $\mathrm{P}>0.2$ & $\mathrm{P}>0.2$ & $\mathrm{P}>0.2$ \\
\hline
\end{tabular}


Table 10

Effect of Lacarnol on Cerebral Metabolism

\begin{tabular}{l|c|c|c|c|c}
\hline \multicolumn{2}{l}{} & $\mathrm{Agl}$ & $\mathrm{A}-\mathrm{Vgl}$ & $\mathrm{CMRgl}$ \\
\hline $\begin{array}{l}\text { Mean value } \\
\text { before administration }\end{array}$ & 82 & 16 & 3.77 \\
\hline $\begin{array}{l}\text { Mean value } \\
\text { after administration }\end{array}$ & 86 & 7 & 3.18 \\
\cline { 2 - 5 } & $\mathrm{A}-\mathrm{VO}_{2}$ & $\mathrm{CMRO}_{2}$ & $\mathrm{CDO}_{2}$ & $\mathrm{ERO}_{2}$ & $\mathrm{CRQ}$ \\
\hline $\begin{array}{l}\text { Mean value } \\
\text { before administration }\end{array}$ & 6.70 & 3.62 & 9.71 & 38.2 & 0.91 \\
\hline $\begin{array}{l}\text { Mean value } \\
\text { after administration }\end{array}$ & 7.31 & 3.30 & 7.92 & 41.7 & 1.01 \\
\hline
\end{tabular}

Table 10 shows the effect of Lacarnol on cerebral metabolișm. The glucose consumption in the brain decreased from average 8.75 to 3.18 but the change was not particular. No marked change was seen in the oxygen consumption in the brain (3.62 to 3.30 ) but a decrease was observed in the oxygen supply.

The effects of Parmanil, oxyethyl-theophylline and Lacarnol on cerebral circulation and metabolism were investigated by $\mathrm{N}_{2} \mathrm{O}$-method though remarkable increase of the cerebral blood flow could not be observed. Therefore it was difficult to understand the clinical effect of Parmanil from this point of view. However, the results obtained by the $\mathrm{N}_{2} \mathrm{O}$-method concerned all the mean value of the whole brain, thus, it may be considered that the effect can not be known exactly if the preparation is effective particularly on the local disturbance of cerebral vessels.

\section{DISCUSSION AND CONCLUSION}

(1) Five patients who had had disturbance of cerebral blood vessel received 3 tablets of Parmanil daily. Improvement was observed in some cases in the movement, disturbance of speech and mental disturbance but the effect could not be concluded at the present stage.

(2) As the one of the methods to determine the clinical effect of parmanil, its influences on cerebral circulation was investigated by $\mathrm{N}_{2} \mathrm{O}$-method. With a single injection of parmanil a decrease of cerebral blood flow was observed, though, no change was seen in cerebral metabolism. After a double injection the cerebral blood flow decreased in some cases and increased in the other cases. It was found that the increase was observed in all cases which had showed a decrease of the 
cerebral blood flow less than 45.2 before injection.

(3) The effects of each component of Parmanil, oxyethyl-theophylline and nucleoside on cerebral circulation were investigated by $\mathrm{N}_{2} \mathrm{O}$-method. With intravenous injection of $0.22 \mathrm{~g}$ of oxyethyl-theophylline a decrease of cerebral blood flow was observed, however, no marked change was seen in cerebral metaboliam. With intravenous injection of $10 \mathrm{cc}$ Lacarnol-Forte cerebral blood flow decreased slightly but no remarkable change was observed in cerebral metabolism.

(4) From the above results it can be considered that in case of disturbance of cerebral blood flow the cerebral circulation may be improved after the use of a comparatively large amount of Parmanil. However, further investigation must be required as the mode of action of Parmanil can not yet be concluded from the results obtained so far.

\section{REFERENCE}

1. Kety, S. S., and Schmidt, C. F.: J. Clin. Invest. 27: 489, 1948.

2. Aizawa, T.: Problems of cerebral circulation (Published by Kanahara Shuppan), 1956.

3. Clarke, R. L., Hughes, N. C. and Togothetopouloo, J.: Lancet, 267: 567, 1954.

4. Aizawa et al.: Unpublished. 